Article

\title{
Switching from Electron to Hole Transport in Solution-Processed Organic Blend Field-Effect Transistors
}

\author{
Julia Fidyk ${ }^{1}{ }^{\oplus}$, Witold Waliszewski ${ }^{1}$, Piotr Sleczkowski ${ }^{1}{ }^{\circledR}$, Adam Kiersnowski $^{2,3}{ }^{\circledR}$, \\ Wojciech Pisula 1,4 (D) and Tomasz Marszalek $1,4, *$ (D) \\ 1 Department of Molecular Physics, Faculty of Chemistry, Lodz University of Technology, Zeromskiego 116, \\ 90-924 Lodz, Poland; julia.fidyk@dokt.p.lodz.pl (J.F.); witold.waliszewski@dokt.p.lodz.pl (W.W.); \\ piotr.sleczkowski@p.lodz.pl (P.S.); pisula@mpip-mainz.mpg.de (W.P.) \\ 2 Leibniz Institute of Polymer Research, Hohe Str. 6, 01069 Dresden, Germany; kiersnowski@ipfdd.de \\ 3 Wroclaw University of Science and Technology, Wybrzeze Wyspianskiego 27, 50-370 Wroclaw, Poland \\ 4 Max Planck Institute for Polymer Research, Ackermannweg 10, 55128 Mainz, Germany \\ * Correspondence: marszalek@mpip-mainz.mpg.de
}

Received: 26 August 2020; Accepted: 7 November 2020; Published: 11 November 2020

\begin{abstract}
Organic electronics became an attractive alternative for practical applications in complementary logic circuits due to the unique features of organic semiconductors such as solution processability and ease of large-area manufacturing. Bulk heterojunctions $(\mathrm{BHJ})$, consisting of a blend of two organic semiconductors of different electronic affinities, allow fabrication of a broad range of devices such as light-emitting transistors, light-emitting diodes, photovoltaics, photodetectors, ambipolar transistors and sensors. In this work, the charge carrier transport of $\mathrm{BHJ}$ films in field-effect transistors is switched from electron to hole domination upon processing and post-treatment. Low molecular weight n-type $N, N^{\prime}$-bis(n-octyl)-(1,7\&1,6)-dicyanoperylene-3,4:9,10-bis(dicarboximide) (PDI8-CN 2 ) was blended with p-type poly[2,5-bis(3-tetradecylthiophene-2-yl)thieno[3,2-b]thiophene] (PBTTT-C 14 ) and deposited by spin-coating to form BHJ films. Systematic investigation of the role of rotation speed, solution temperature, and thermal annealing on thin film morphology was performed using atomic force microscopy, scanning electron microscopy, and grazing incidence wide-angle $X$-ray scattering. It has been determined that upon thermal annealing the BHJ morphology is modified from small interconnected PDI8-CN 2 crystals uniformly distributed in the polymer fraction to large planar PDI8-CN2 crystal domains on top of the blend film, leading to the switch from electron to hole transport in field-effect transistors.
\end{abstract}

Keywords: organic electronics; bulk heterojunction; charge carrier transport; organic field-effect transistor; film morphology

\section{Introduction}

Electronics based on organic semiconductors (OSCs) offer advantages such as mechanical flexibility, low cost and large-area fabrication by solution processing [1-5]. Organic light-emitting diodes, solar cells, memory devices and organic field-effect transistors (OFETs) are constantly improved via synthesis of new semiconductors as well as development of novel device architectures, thin-film processing and postprocessing techniques [5-10]. OFETs exhibiting charge carrier mobilities comparable to amorphous silicon $\left(>1 \mathrm{~cm}^{2} / \mathrm{Vs}\right)$ became attractive for future applications in electronics, circumventing conventional vacuum and photolithographic fabrication processes. Especially unipolar [11,12] and ambipolar [13-16] OFETs became important for complementary logic circuits and inverters. Although most OSCs intrinsically conduct electrons and holes, the vulnerability of electron carriers to ambient conditions (i.e., the detrimental effects of $\mathrm{O}_{2}$ and $\mathrm{H}_{2} \mathrm{O}$ ) results in serious degradation of the n-type transport 
in devices [4,17]. Additionally, an alignment of the electrode work function with the HOMO and LUMO levels of the semiconductor is necessary for an efficient injection of electrons and holes into the active layer [18-20]. This means that the type of unipolar conduction, $\mathrm{n}$ - or $\mathrm{p}$-type, of an organic semiconducting film is fixed after the device fabrication and a subsequent modification is challenging due to the misalignment of the metal work function.

An alternative approach consists of blending two organic semiconductors into a bulk heterojunction (BHJ) morphology with phase separated p- and n-type fractions [16,21,22]. This method is used frequently not only in light emitting transistors, light-emitting diodes and photovoltaics [22-27], but also applied to achieve a balanced transport of electrons and holes in ambipolar OFETs [28]. In most cases, BHJs are fabricated from a solution of polymer-polymer or polymer-low molecular weight semiconductor blend. The BHJ morphology strongly determines the charge carrier transport in OFETs. Since the charge carrier transport in OFETs occurs parallel to the substrate, the $\mathrm{BHJ}$ interface needs to be adapted accordingly to avoid scattering of charges and interruption in the charge carrier path [28]. Further essential requirements are a contact of each semiconductor phase with the source and drain electrodes and a continuous percolation path for each type of charge carrier. Most studies focus on the impact of the blend ratio of the semiconducting components on the $\mathrm{BHJ}$ film morphology and charge carrier transport in OFETs [28-30]. However, the influence of processing parameters has not been studied well so far.

So far, BHJs have only been used to fabricate ambipolar OFETs [16,28,31] with a balanced transport of holes and electrons. In our novel approach, BHJs are exploited to control the type of unipolar conduction by tuning the blend morphology, even after device fabrication. Moreover, we demonstrate for the first time the possibility of switching from unipolar electron to unipolar hole transport in the solution-processed BHJ OFETs. The transition from n- to p-type device behavior is achieved by well-controlled changes in the BHJ morphology induced through thermal post-treatment. The possibility of switching the conduction type in solution-processed OFETs by post-treatment [32] is important for the fabrication of logic circuits such as complementary inverters. In this work, we demonstrate the possibility of switching from electron to hole transport in solution-processed BHJ OFETs. The transition from n- to p-type device behavior is achieved by controlled changes in the $\mathrm{BHJ}$ morphology induced through thermal post-treatment. Blends of p-type poly[2,5-bis(3-tetradecylthiophene-2-yl)thieno[3,2-b]thiophene] (PBTTT- $\mathrm{C}_{14}$ ) and n-type low molecular weight $N, N^{\prime}$-bis(n-octyl)-(1,7\&1,6)-dicyanoperylene-3,4:9,10-bis(dicarboximide) (PDI8-CN ${ }_{2}$ ) were solution cast to form PBTTT- $\mathrm{C}_{14}:$ PDI8- $\mathrm{CN}_{2}$ BHJ films in OFETs. Both compounds were chosen due to their chemical stability, good field-effect mobility, and solution processability [33-38]. Systematic variation of rotation speed, solution temperature, and thermal annealing allowed the identification of key processing parameters to control the BHJ film morphology. It was observed that a prolonged drying time and lower spin-coating speed facilitated the formation of larger PDI8-CN 2 crystals, while a high solution temperature led to the growth only of small PDI8- $\mathrm{CN}_{2}$ crystals immersed in the polymer fraction. Thermal annealing after the film deposition significantly changed the blend morphology and induced a switch from electron to hole transport in OFETs.

\section{Materials and Methods}

PBTTT-C ${ }_{14}$ was purchased from Sigma-Aldrich (Saint Louis, MO, USA) and PDI8-CN $\mathrm{CN}_{2}$ as ActivInk N1200 from Polyera Corporation (Skokie, IL, USA) (Figure 1a,b). Both compounds were used as received. The HOMO level of $-5.1 \mathrm{eV}$ for PBTTT- $\mathrm{C}_{14}$ [39] and LUMO of $-4.3 \mathrm{eV}$ for PDI8-CN $\mathrm{CN}_{2}$ [40] were properly aligned with the work function of gold $(\mathrm{WF}=-5.1 \mathrm{eV})$ for injection of electrons and holes into the BHJ film (Figure 1c). The energy gap between these levels was less than $1 \mathrm{eV}$ preventing formation of the charge carrier traps at semiconductor/electrode interface $[16,20,41]$. It has been reported that the effective energy gap allowing charge transfer and increase in the conductivity is below $0.6 \mathrm{eV}[42,43]$. Due to the relatively high energy gap of $0.8 \mathrm{eV}$ between HOMO of PBTTT- $\mathrm{C}_{14}(-5.1 \mathrm{eV})$ and LUMO of 
PDIC8-CN $2(-4.3 \mathrm{eV})$ a charge transfer was excluded in our case. A concentration of $20 \mathrm{mg} / \mathrm{mL}$ in 1,2-dichlorobenzene of PBTTT- $\mathrm{C}_{14}$ and PDI8- $\mathrm{CN}_{2}(50 / 50 \mathrm{wt} \%)$ was used for the solution processing.

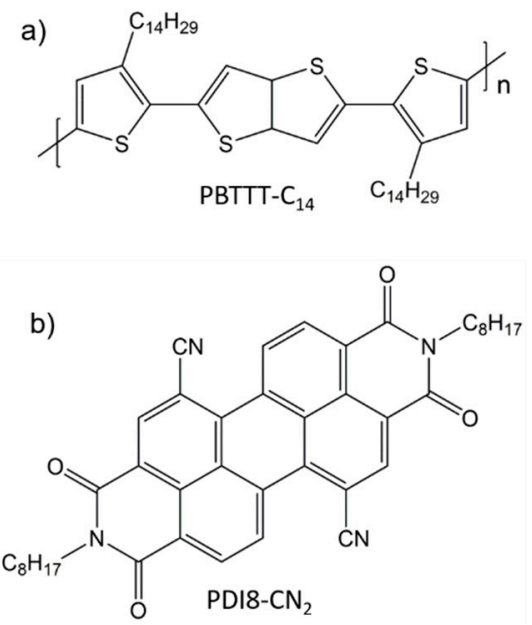

c)

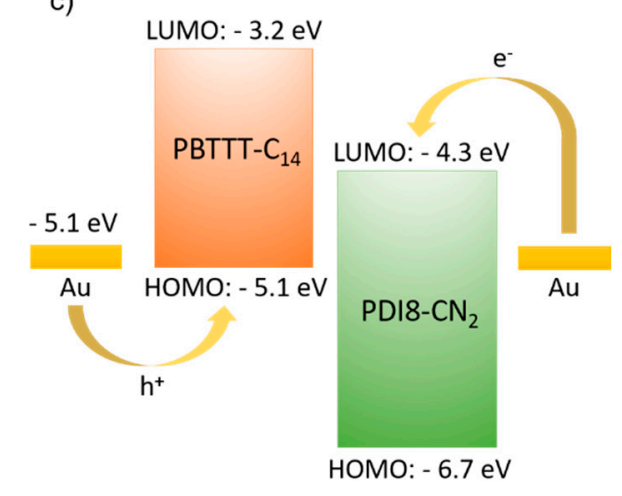

Figure 1. Chemical structures of (a) p-type PBTTT-C 14, (b) n-type PDI8- $\mathrm{CN}_{2}$ and (c) an energy level diagram of the bulk heterojunction (BHJ) organic field-effect transistor (OFET).

Highly p-doped silicon wafers with thermally grown $300 \mathrm{~nm}$ silicon dioxide (capacitance of $11 \mathrm{nF} \mathrm{cm}^{-2}$ ) were used as substrates for the device fabrication. The substrates were ultrasonically cleaned using standard procedure ( $15 \mathrm{~min}$ acetone, $15 \mathrm{~min}$ isopropanol) and dried with $\mathrm{N}_{2}$. BHJ films were deposited by spin-coating at different rotation speeds ranging from 1000 to $6000 \mathrm{rpm}$ at a solution temperature from 80 to $180{ }^{\circ} \mathrm{C}$ in the glovebox in nitrogen atmosphere. Samples fabricated at different solution temperatures were annealed on a hotplate in the glovebox for $1 \mathrm{~h}$ at $140^{\circ} \mathrm{C}$. For the investigation of the post-treatment on the BHJ morphology, samples fabricated at 3000 and $4000 \mathrm{rpm}$ from solution at 100 and $120^{\circ} \mathrm{C}$ were annealed at $200^{\circ} \mathrm{C}$ for $2 \mathrm{~h}$ on a hotplate in the glovebox. For one set of samples fabricated at $4000 \mathrm{rpm}$ from solution at $100^{\circ} \mathrm{C}$, the substrates were additionally modified by octadecyltrichlorosilane (OTS) (Sigma Aldrich Chemie Gmbh, Munich, Germany). After standard cleaning, these substrates were immersed in piranha solution (a mixture of $3: 7(v / v)$ of $30 \% \mathrm{H}_{2} \mathrm{O}_{2}$ and $98 \% \mathrm{H}_{2} \mathrm{SO}_{4}$ ) for $30 \mathrm{~min}$. Subsequently, the silicon wafers were rinsed a few times with deionized water and methanol, dried with the nitrogen flow and immersed in an unstirred solution of $0.5 \%$ OTS in a mixture of chloroform and hexane $(1: 4(v / v))$ for $30 \mathrm{~min}$. After the modification, the substrates were additionally rinsed with chloroform and dried with nitrogen flow.

Bottom gate top contact (BGTC) configuration was employed for the BHJ OFETs. Source-drain gold electrodes were thermally evaporated through shadow masks to the nominal thickness of $80 \mathrm{~nm}$ (controlled using quartz crystal microbalance). OFETs with channel width (W) of $1 \mathrm{~mm}$ and variable channel lengths (L) of 10-30 $\mu \mathrm{m}$ were fabricated and further characterized using Keithley 4200 source meter (Keithley Instruments, Inc., Cleveland, OH, USA) connected to a needle-probe station. Charge carrier mobilities were calculated from the transfer characteristics in the saturation regime, using the following formula [44]:

$$
\mu_{\text {sat }}=\frac{2 I_{D S} L}{W C_{i}\left(V_{G}-V_{t h}\right)^{2}}
$$

where $\mu_{\text {sat }}$ stands for the charge carrier mobility, $I_{D S}$ is the drain current, $W$ the channel width, $L$ the channel length, $C_{i}$ the capacitance of gate dielectric, $V_{G}$ the gate voltage and $V_{t h}$ the threshold voltage.

The LEO Gemini 1530 Scanning Electron Microscope (SEM) (Carl Zeiss AG, Oberkochen, Deutschland) and Veeco Dimension 3100 Atomic Force Microscope (AFM) (Digital Instruments, Santa Barbara, CA, USA) were used to investigate the morphology and thickness of the BHJ thin films. Grazing incidence wide-angle X-ray scattering (GIWAXS) was performed at the DELTA Synchrotron 
(Dortmund, Germany), beamline BL09. The photon energy was set to $10 \mathrm{keV}(\lambda=1.24 \AA)$. During the measurements, the samples were under vacuum ( 1 mbar). The incident angle $\left(\alpha_{\mathrm{i}}\right)$ of the $\mathrm{X}$-ray beam was adjusted individually for each sample in the range of $0.19^{\circ}-0.20^{\circ}$. The scattered intensity was recorded by a 2D image plate (MAR345, marXperts $\mathrm{GmbH}$, Norderstedt, Germany). The exposure time was $800 \mathrm{~s}$. The $q$-range $\left(q=4 \times \pi \times \sin \theta \times \lambda^{-1}\right)$ was calibrated using silver behenate standard. The data was processed and analyzed using Datasqueeze (University of Pennsylvania, Philadelphia, PA, USA) and OriginPro (OriginLab Corporation, Northampton, MA, USA).

\section{Results and Discussion}

\subsection{Role of Rotation Speed}

The molecular organization and the crystallization kinetics of the conjugated molecules can be controlled during spin-coating parameters through tuning the amount of residual solvent after the film formation. Since the amount of solvent and drying time are closely related to the spin-coating speed, in this study, the BHJ films were deposited at various rotation speeds between 1000-6000 rpm. A solution temperature of $100{ }^{\circ} \mathrm{C}$ ensured sufficient dissolution and mixing of the semiconductors. Scanning electron microscopy (SEM) images in Figure 2 show the effect of the rotation speed on the crystallization of PDI8-CN $\mathrm{CN}_{2}$ at the top film surface in the presence of PBTTT- $\mathrm{C}_{14}$. Although the rotation speed did not affect the PBTTT- $\mathrm{C}_{14}$ morphology, a higher rotation speed reduced the amount of solution remaining on the substrate during spin-coating and decreased the drying time leading to the growth of only small PDI8- $\mathrm{CN}_{2}$ crystals. Additionally, less solvent remaining in the blend lowered the recrystallization process.

As evident from Figure 2, in nonannealed BHJ films the PDI8- $\mathrm{CN}_{2}$ crystal size decreased with increasing rotation speed. Concerning the $\mathrm{BHJ}$ formation, the interconnected and uniformly distributed PDI8-CN $\mathrm{CN}_{2}$ crystals in the PBTTT- $\mathrm{C}_{14}$ fraction ensured an electron transport in the OFETs [28]. Typical n-type transfer characteristics are presented in Figure S1. Despite evident differences in BHJ morphology by varying the rotation speed, only minor changes in field-effect mobility were observed (Table S1). The highest n-type mobility of $2 \times 10^{-4} \mathrm{~cm}^{2} /(\mathrm{Vs})$ was determined for rotation speeds of 3000 and $4000 \mathrm{rpm}$. In these conditions, the optimum size and distribution of the PDI8-CN $\mathrm{CN}_{2}$ crystals created the necessary pathways for electrons. However, no hole transport was observed for this series of transistors.
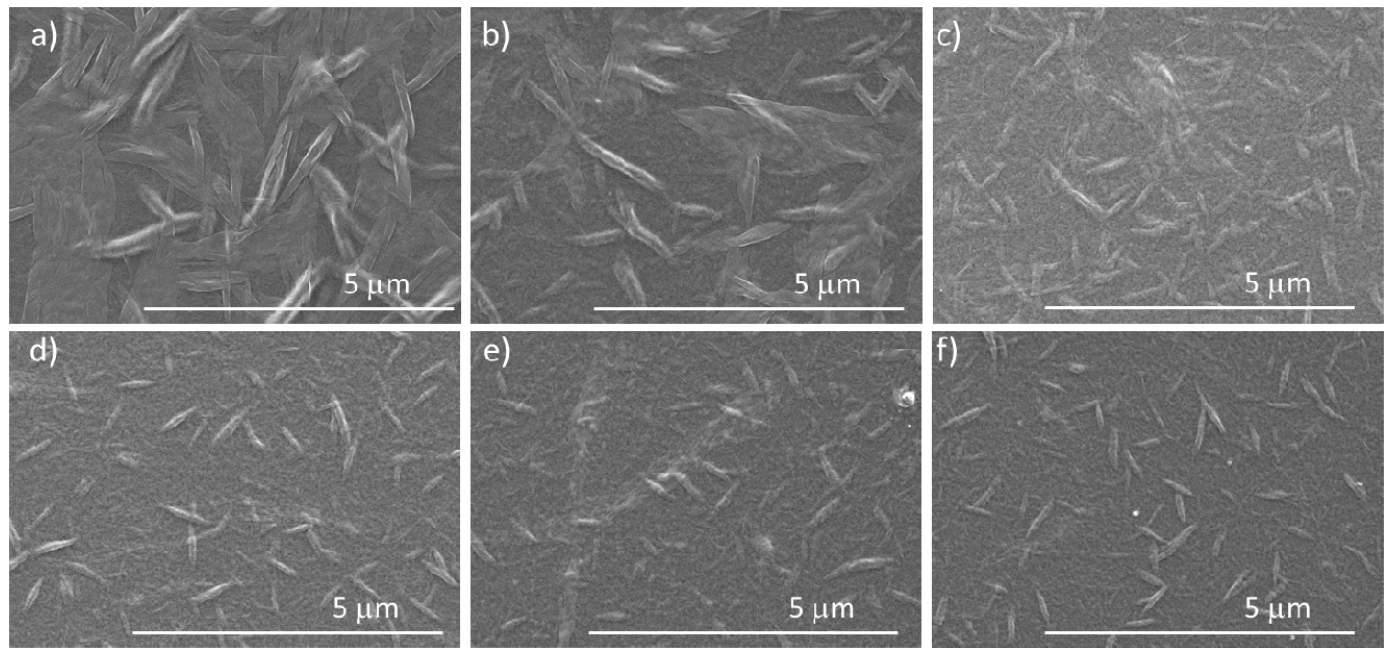

Figure 2. SEM images of PBTTT- $\mathrm{C}_{14}: \mathrm{PDI} 8-\mathrm{CN}_{2} \mathrm{BHJ}$ films obtained by spin-coating from a $100{ }^{\circ} \mathrm{C}$ hot solution at rotation speeds of (a) $1000 \mathrm{rpm}$, (b) $2000 \mathrm{rpm}$, (c) $3000 \mathrm{rpm}$, (d) $4000 \mathrm{rpm}$, (e) $5000 \mathrm{rpm}$, (f) $6000 \mathrm{rpm}$. 


\subsection{Impact of Solution Temperature}

The solution is usually heated to improve the solubility of semiconductors and to prevent aggregation prior to deposition [34] or to accelerate the solvent evaporation. In this study, the effect of solution temperature, which varied from 80 to $180^{\circ} \mathrm{C}$, on the $\mathrm{BHJ}$ morphology was investigated for the rotation speed of $3000 \mathrm{rpm}$ leading to the highest n-type mobility within the series. Figure 3 shows atomic force microscopy (AFM) images of the surface of $\mathrm{BHJ}$ films obtained for different solution temperatures at $3000 \mathrm{rpm}$. After the deposition, each sample was thermally annealed at $140{ }^{\circ} \mathrm{C}$ for $1 \mathrm{~h}$ to completely remove solvent residues.
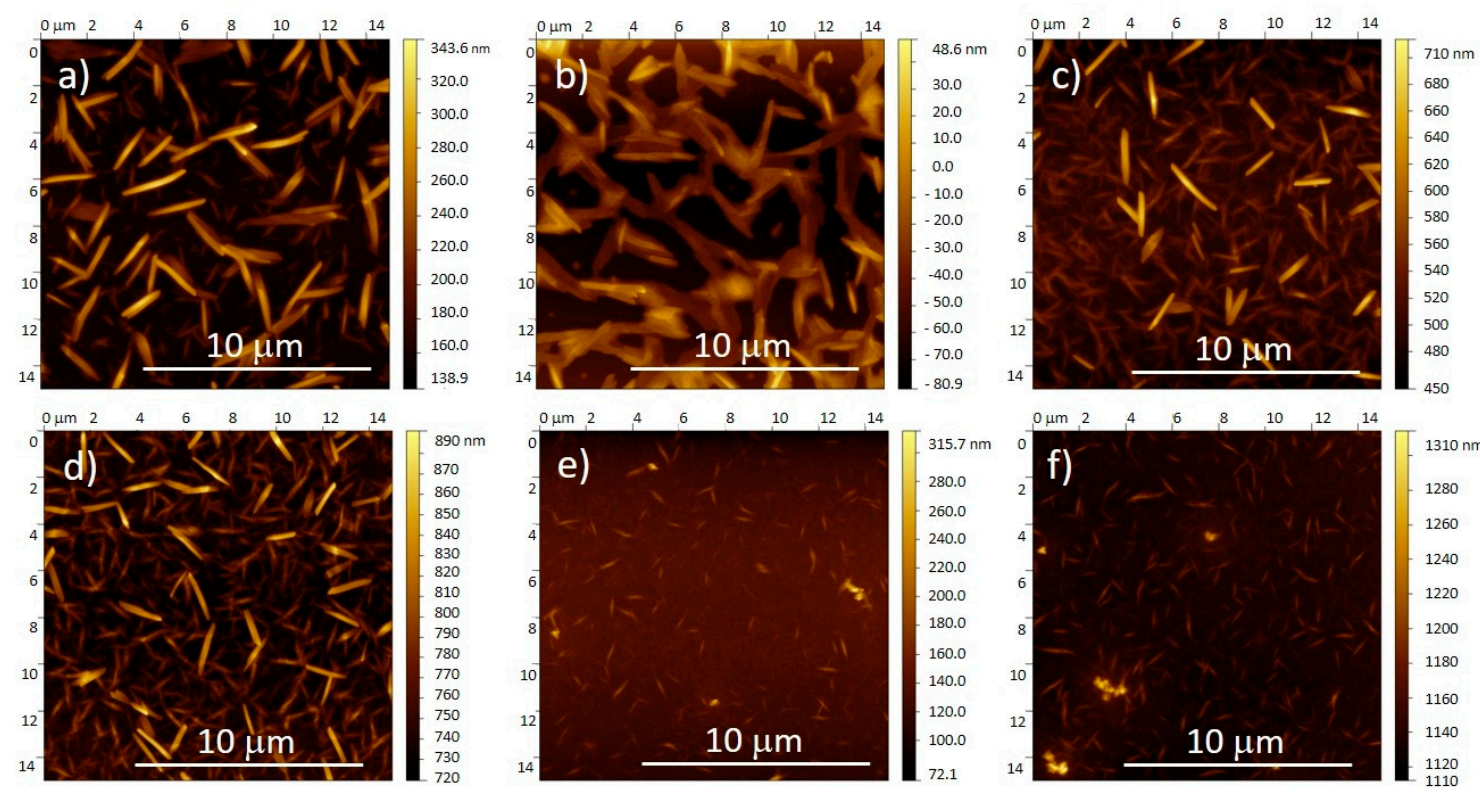

Figure 3. Atomic force microscopy (AFM) height images of PBTTT- $\mathrm{C}_{14}: \mathrm{PDI}_{8}-\mathrm{CN}_{2} \mathrm{BHJ}$ films deposited at $3000 \mathrm{rpm}$ and solution temperatures of (a) $80{ }^{\circ} \mathrm{C}$, (b) $100{ }^{\circ} \mathrm{C},(\mathbf{c}) 120^{\circ} \mathrm{C}$, (d) $140{ }^{\circ} \mathrm{C},(\mathbf{e}) 160{ }^{\circ} \mathrm{C}$, (f) $180^{\circ} \mathrm{C}$.

The increase in solution temperature from 80 to $140{ }^{\circ} \mathrm{C}$ and subsequent annealing did not affect the surface morphology of the PBTTT-C $14:$ PDI8-CN ${ }_{2}$ BHJ. However, for films cast at 160 and $200{ }^{\circ} \mathrm{C}$, the deposition temperature was higher than the annealing temperature. For this reason, $\mathrm{PDI} 8-\mathrm{CN}_{2}$ could not recrystallize during the post-treatment. Additionally, the increase of the solution temperature accelerated the solvent evaporation during the deposition. For temperatures above $140{ }^{\circ} \mathrm{C}$, the growth kinetics of PDI8- $\mathrm{CN}_{2}$ were much faster leading to significantly smaller crystal needles immersed in the PBTTT-C 14 phase.

Despite the interconnected PDI8- $\mathrm{CN}_{2}$ crystals in the annealed $\mathrm{BHJ}$ films for solution temperatures below $160{ }^{\circ} \mathrm{C}$, only a hole transport was found (Figure S2 and Table S2). Although the surface morphology of the $\mathrm{BHJ}$ did not differ significantly in the temperature range of $80-140{ }^{\circ} \mathrm{C}$, a maximum hole charge carrier mobility of $1 \times 10^{-3} \mathrm{~cm}^{2} /(\mathrm{Vs})$ was determined for $100{ }^{\circ} \mathrm{C}$ (Figure 4 ). For samples cast above $140^{\circ} \mathrm{C}$ no field effect was observed. Evident changes in blend morphology were mainly ascribed to the size of PDI8- $\mathrm{CN}_{2}$ crystals, while the PBTTT- $\mathrm{C}_{14}$ morphology remained unaffected. It was assumed that despite similarities in the film topography, the solution temperature influenced the morphology and molecular organization of the bulk BHJ film. Since the charge carrier transport in OFETs occurs near the dielectric/semiconductor interface [45], differences in the interface morphology can lead to changes in the field-effect mobility. 


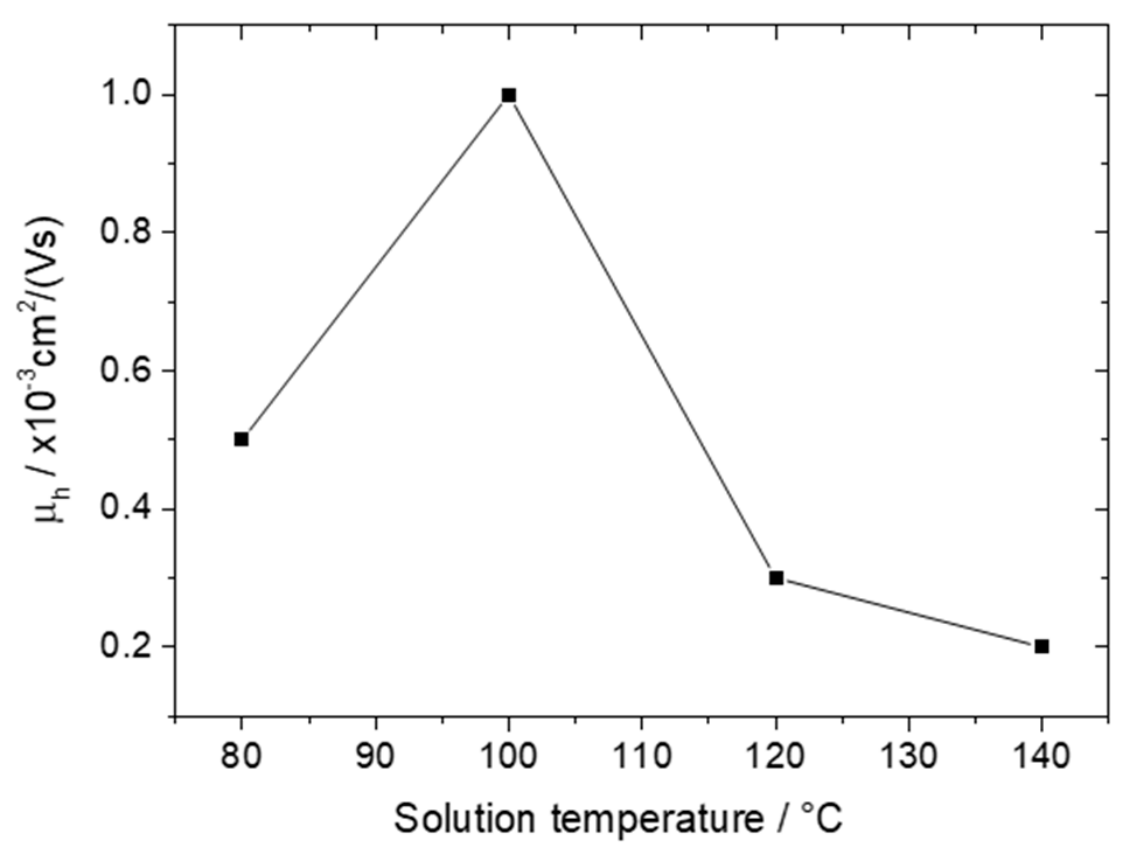

Figure 4. Field-effect mobility of holes as function of solution temperature for PBTTT-C $14: \mathrm{PDI}_{8}-\mathrm{CN}_{2}$ $\mathrm{BHJ}$ films deposited at $4000 \mathrm{rpm}$ and thermally annealed at $140{ }^{\circ} \mathrm{C}$.

\subsection{Effect of Thermal Annealing}

The annealing process is mostly used to remove residual solvent and to improve the molecular organization in thin organic semiconducting films before their use in electronic devices $[16,46]$. For a better understanding of the change from electron to hole transport in the $\mathrm{BHJ}$ films observed after thermal post-treatment, the annealing temperature was increased to $200{ }^{\circ} \mathrm{C}$ (Figure S3) above the PBTTT- $\mathrm{C}_{14}$ transition to the liquid crystal phase [35-37]. For an annealing temperature of $140{ }^{\circ} \mathrm{C}$, which is lower than the solution temperatures of 160 and $200{ }^{\circ} \mathrm{C}$, noticeable differences in the PBTTT-C 14 :PDI8-CN $\mathrm{CN}_{2}$ morphology were observed (Figure 3). However, if the annealing temperature of $200{ }^{\circ} \mathrm{C}$ was higher than the solution temperature, the film morphology of the $\mathrm{BHJ}$ was independent of the lower solution temperature (Figure S3). Although the morphology was similar to blend films annealed at $140{ }^{\circ} \mathrm{C}$, the elevated temperature of $200{ }^{\circ} \mathrm{C}$ enabled recrystallization of PDI8-CN ${ }_{2}$ and also in blends cast at 160 and $200^{\circ} \mathrm{C}$. The PBTTT- $\mathrm{C}_{14}$ polymer backbones became more mobile at film annealing at $200{ }^{\circ} \mathrm{C}$ above the liquid crystal phase transition, facilitating a reorganization of PDI8-CN 2 into needle-like crystals on the surface of the BHJ film.

The morphology transition of the optimized-BHJ films (fabricated at $3000 \mathrm{rpm}$ from solutions at 100 or $120^{\circ} \mathrm{C}$ ) upon annealing is evident from SEM images in Figure 5. Before annealing, the blends revealed a network of interconnected PDI8-CN $\mathrm{CN}_{2}$ crystals distributed in the PBTTT- $\mathrm{C}_{14}$ fraction (Figures 2 and $5 \mathrm{a}, \mathrm{c}$ ). Annealing at $200{ }^{\circ} \mathrm{C}$ promoted growth of the PDI8- $\mathrm{CN}_{2}$ crystals and led to evident phase-separation of blend components as marked by arrows in Figure $5 \mathrm{~d}$. The recrystallization of PDI8- $\mathrm{CN}_{2}$ upon annealing resulted in larger crystals (Figure $5 b, d$ ) as confirmed by GIWAXS results (Figure 6). 

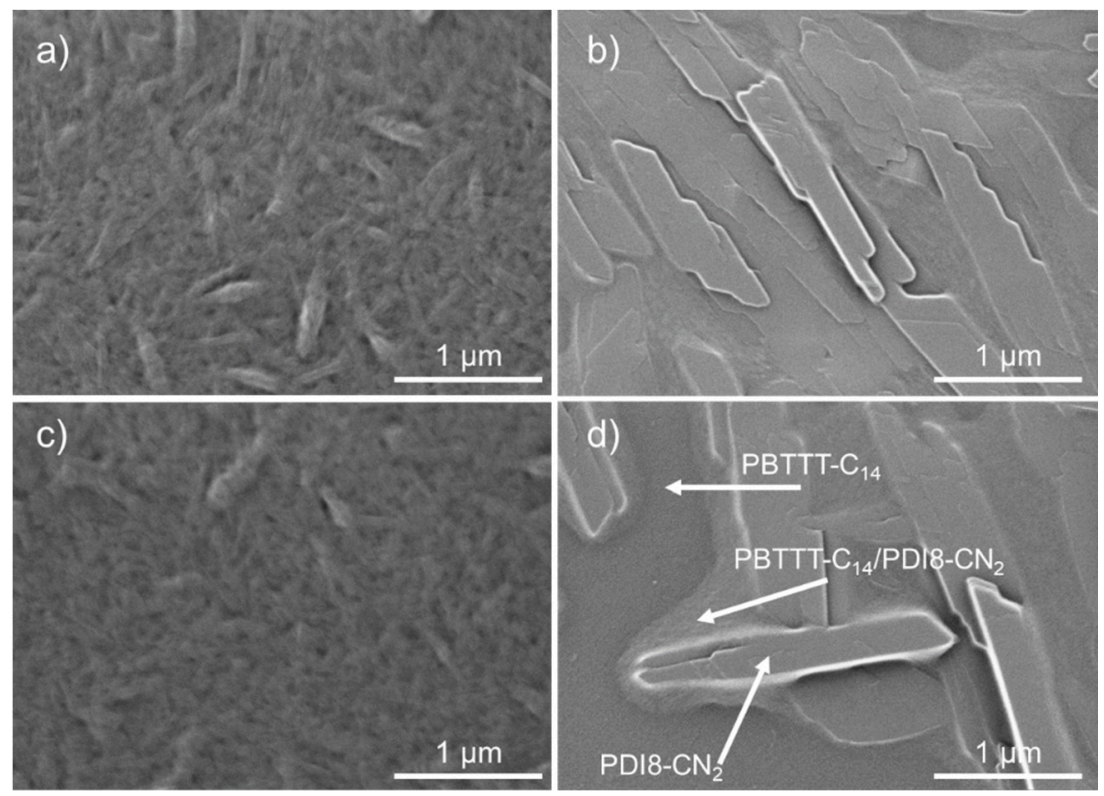

Figure 5. SEM images of PBTTT- $\mathrm{C}_{14}: \mathrm{PDI} 8-\mathrm{CN}_{2} \mathrm{BHJ}$ films cast at solution temperatures of $(\mathbf{a}, \mathbf{b}) 100^{\circ} \mathrm{C}$ and $(\mathbf{c}, \mathbf{d}) 120^{\circ} \mathrm{C} ;(\mathbf{a}, \mathbf{c})$ as-cast, $(\mathbf{b}, \mathbf{d})$ after thermal annealing at $200^{\circ} \mathrm{C}$ (the two phase separated fractions are indicated).

The SEM images (Figure 5a,c) show small PDI8- $\mathrm{CN}_{2}$ crystals in the as-cast films as confirmed by the low intensity of corresponding GIWAXS peaks and their relatively broad azimuthal distribution as well as Scherrer's widths (Figure 6). Thermal annealing of the films at $20{ }^{\circ} \mathrm{C}$ initiated a crystal growth which was manifested by a significant increase of intensity as well as narrowing of the azimuthal distribution and Scherrer breadths of the PDI8- $\mathrm{CN}_{2}$ peaks visible in the GIWAXS patterns (Figure 6). A similar effect was observed in P3HT-PDI8- $\mathrm{CN}_{2}$ blends where an Ostwald ripening-like aggregation of smaller crystals forming eventually large crystal domains was reported [47]. Heating the film above the liquid crystal phase transition of PBTTT- $\mathrm{C}_{14}$ reduced the viscosity of the film, which probably facilitated migration of PDI8- $\mathrm{CN}_{2}$ to its surface and enabled effective crystal growth on top. As revealed by both SEM and GIWAXS (Figures 5 and 6) a crystal growth through Ostwald ripening enhanced the planar growth of PDI8-CN $\mathrm{CN}_{2}$ crystals on top of the BHJ films. In addition to changes in the PDI8- $\mathrm{CN}_{2}$ morphology, annealing of the films influenced the crystallinity of the polymer. The GIWAXS patterns in Figure 6 reveal an ordered structure and edge-on dominated chain orientation of PBTTT-C $\mathrm{C}_{14}$ both in pure polymer and in the PBTTT- $\mathrm{C}_{14}: \mathrm{PDI} 8-\mathrm{CN}_{2}$ films. The positions of the meridional (h00) Bragg series (Figure 6a) and the equatorial diffuse reflection profile corresponding to the $\pi$-stacking distance $\left(\mathrm{d}_{\pi-\pi}\right)$ suggested that alkyl side chains of PBTTT- $\mathrm{C}_{14}$ were (at least partly) twisted causing a large separation between the backbones [46]. Deconvolution of the diffuse reflection in the range 1.3-1.7 $\AA^{-1}$ revealed the existence of two components: $d_{\pi-\pi 1}=4.4 \AA$ and $d_{\pi-\pi 2}=3.9 \AA$, which corresponded to twisted and non-twisted side chain configurations, respectively, in the PBTTT- $\mathrm{C}_{14}$ domains [48]. Annealing of the PBTTT- $\mathrm{C}_{14}$ film did not cause significant changes in the polymer packing but caused the polymer crystal domains to grow, mainly along the $a$-lattice vector. That growth was manifested by narrowing of the out-of-plane (meridional) diffraction peaks (cf. Figure $6 \mathrm{a}, \mathrm{b}$ ). Addition of PDI8- $\mathrm{CN}_{2}$ and formation of the $\mathrm{BHJ}$ films did not change the crystal packing of the polymer, but significantly reduced the PBTTT- $\mathrm{C}_{14}$ average crystal domain size in the as-cast films. This decrease can be concluded from two facts: (i) the meridional peaks for PBTTT- $\mathrm{C}_{14}$ were significantly broader in the case of $\mathrm{BHJ}$ film than for the pure polymer (Figure 6a,c), and (ii) the higher order (300 and 400) peaks were missing in the pattern of the as-cast BHJ film (Figure 6c). The strong amorphous halo visible in Figure 6c suggested that in the as-cast $\mathrm{BHJ}$ films a large fraction of PBTTT- $\mathrm{C}_{14}$ remained disordered. Annealing of the $\mathrm{BHJ}$ films caused crystals to grow. Comparison of Figure $6 \mathrm{~b}$,d indicated that the h00 (meridional) peaks 
observed for the annealed pure PBTTT- $\mathrm{C}_{14}$ film (Figure $6 \mathrm{~b}$ ) were broader than those for the annealed BHJ film (Figure $6 \mathrm{~d}$ ). This suggested that the size of polymer crystal domains in the annealed $\mathrm{BHJ}$ film was larger than in the pure PBTTT- $\mathrm{C}_{14}$ film.
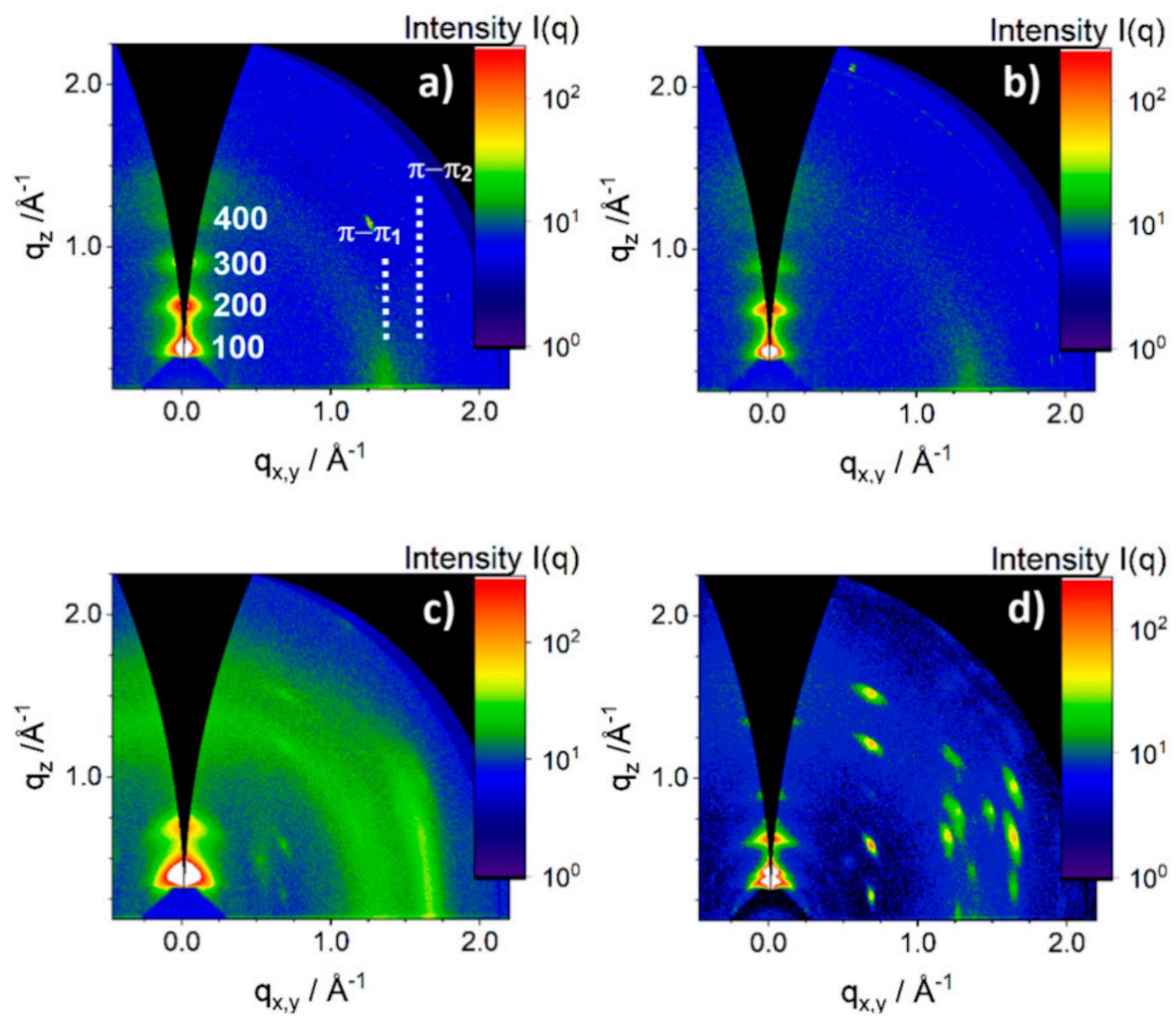

Figure 6. Grazing incidence wide-angle X-ray scattering (GIWAXS) patterns of PBTTT- $\mathrm{C}_{14}$ spin coated at $3000 \mathrm{rpm}$ from a $100{ }^{\circ} \mathrm{C}$ hot solution (a) before and (b) after annealing at $200{ }^{\circ} \mathrm{C}$ and PBTTT- $\mathrm{C}_{14}$ :PDI8- $\mathrm{CN}_{2}$ spin coated at $3000 \mathrm{rpm}$ from solution at $100{ }^{\circ} \mathrm{C}(\mathrm{c})$ before and $(\mathbf{d})$ after annealing at $200^{\circ} \mathrm{C}$. Numbers in the pattern (a) denote the peaks corresponding to h00 Bragg series of PBTTT-C 14 .

The electrical evaluation of the $\mathrm{BHJ}$ films before and after thermal annealing at $200{ }^{\circ} \mathrm{C}$ confirmed the change of conductivity from electron to hole transport. Figure 7 shows output characteristics for the PBTTT- $\mathrm{C}_{14}$ :PDI8-CN $\mathrm{CN}_{2}$ blend film before and after annealing at $200{ }^{\circ} \mathrm{C}$ (transfer characteristics are presented in Figure S5). The strongest difference in electrical properties before and after annealing was observed for the rotation speed of $4000 \mathrm{rpm}$ and solution temperature of $100{ }^{\circ} \mathrm{C}$ (Figure 7 and Figure S4). Before annealing, electron transport was dominating, while after annealing only hole transport was observed.

In the BHJ films two possible conductive paths were formed: for holes through the PBTTT-C ${ }_{14}$ phase and for electrons via the network of PDI8- $\mathrm{CN}_{2}$ crystals. Before annealing, dominant electron transport was established by the PDI8- $\mathrm{CN}_{2}$ crystals, while at the same time the hole conduction was limited due to disordered PBTTT- $\mathrm{C}_{14}$. When the $\mathrm{BHJ}$ film was annealed at $200{ }^{\circ} \mathrm{C}$ in the liquid crystalline phase of PBTTT- $\mathrm{C}_{14}$, the order of the polymer chains was improved, especially in the $\pi$-stacking direction [36,37]. The phase separation between PBTTT- $\mathrm{C}_{14}$ and PDI8- $\mathrm{CN}_{2}$ was also improved leading to the formation of larger PDI8-CN $\mathrm{CN}_{2}$ crystals which were visible in the SEM images (Figure $5 \mathrm{~b}$,d). On the other hand, PDI8-CN $\mathrm{CN}_{2}$ recrystallized into crystal sizes below $25 \mu \mathrm{m}$ which was smaller than the applied 
channel length of the OFETs. Because the PDI8- $\mathrm{CN}_{2}$ crystals were too small to connect the source and drain electrodes, electron transport was not observed. Before annealing, an electron charge carrier mobility of $1 \times 10^{-4} \mathrm{~cm}^{2} /(\mathrm{Vs})$ was determined, while after annealing a hole mobility of $2 \times 10^{-3} \mathrm{~cm}^{2} /(\mathrm{Vs})$ was found. Based on the S-shape of the output characteristics in the positive range of the applied voltage (Figure 7a) the electron transport before annealing could probably be improved by reducing the contact resistance and lowering the charge carrier trapping at dielectric/semiconductor interface.

a)

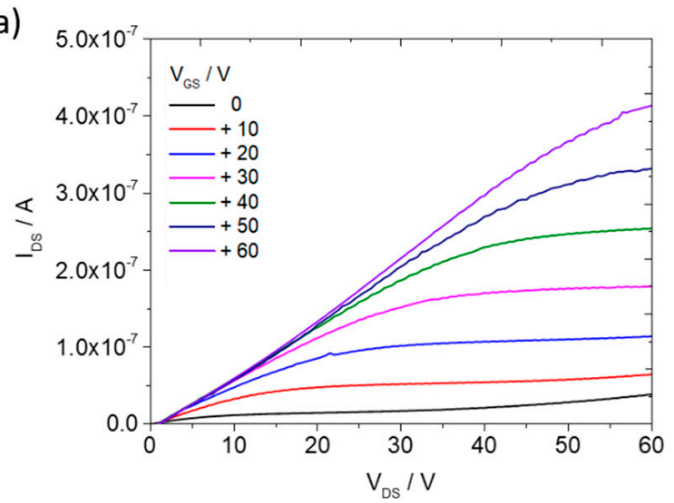

c)

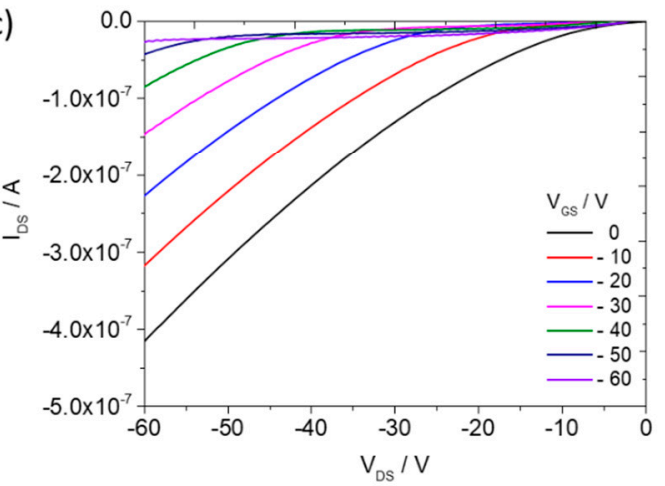

b)

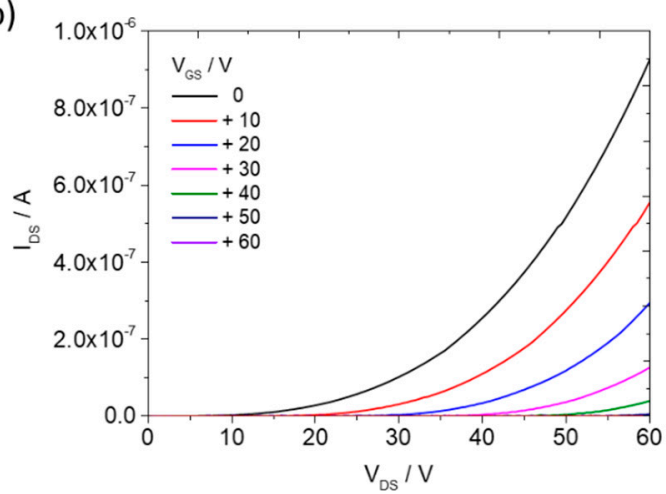

d)

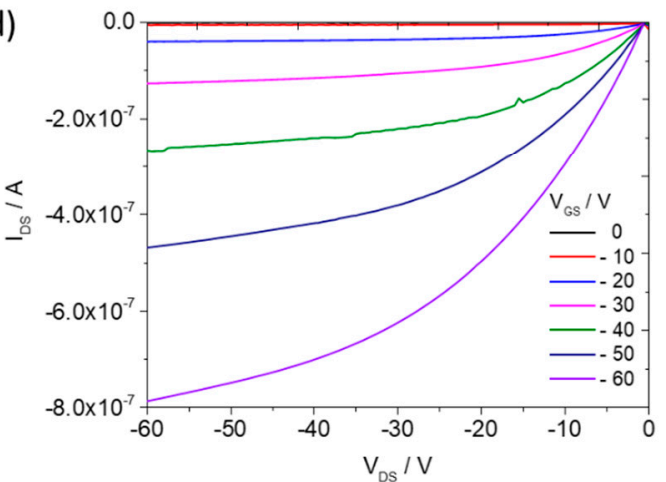

Figure 7. Output characteristics of OFETs based on PBTTT- $\mathrm{C}_{14}:$ PDI8- $\mathrm{CN}_{2} \mathrm{BHJ}$ films spin-coated at $4000 \mathrm{rpm}$ and a solution temperature of $100^{\circ} \mathrm{C}$ for $(\mathbf{a}, \mathbf{b}) \mathbf{n}$ - and $(\mathbf{c}, \mathbf{d})$ p-type regimes; $(\mathbf{a}, \mathbf{c})$ before and (b,d) after thermal annealing at $200^{\circ} \mathrm{C}$.

To improve the transistor operation a self-assembled monolayer (SAM) treatment was applied in order to decrease the electron trapping at the semiconductor/dielectric interface. Figure 8 presents output characteristics of OFETs in BGTC configuration fabricated on the $\mathrm{Si}_{/} \mathrm{SiO}_{2}$ substrate modified by octadecyltrichlorosilane (OTS). The same switching behavior from electron to hole transport upon annealing was observed. The OTS monolayer improved the electron transport as evident from the maximum drain current being almost two orders of magnitude higher than without surface modification. Moreover, an evident saturation region emerged in the output characteristics at lower source-drain voltages. The improved electron charge carrier mobility of $1.5 \times 10^{-2} \mathrm{~cm}^{2} /(\mathrm{Vs})$ was only one order of magnitude lower than for PDI8- $\mathrm{CN}_{2}$ single crystal devices [38]. At the same time, the annealed BHJ films on OTS showed a similar hole mobility of $1 \times 10^{-3} \mathrm{~cm}^{2} /(\mathrm{Vs})$ to devices without surface modification (Figure S6, Table S3). The shape of the p-type output characteristics after annealing indicated additional contact resistance (Figure $8 \mathrm{~d}$ ). Reduced trapping and enhanced operation of the n-type semiconductor indicated problems with the hole injection into PBTTT- $\mathrm{C}_{14}$ [18]. The lower hole mobility in the blend films in comparison to literature values for plain PBTTT- $\mathrm{C}_{14}$ [35] was related to the presence of PDIC8-CN $\mathrm{CN}_{2}$ decreasing the polymer order as proven by GIWAXS (Figure 6). 
a)

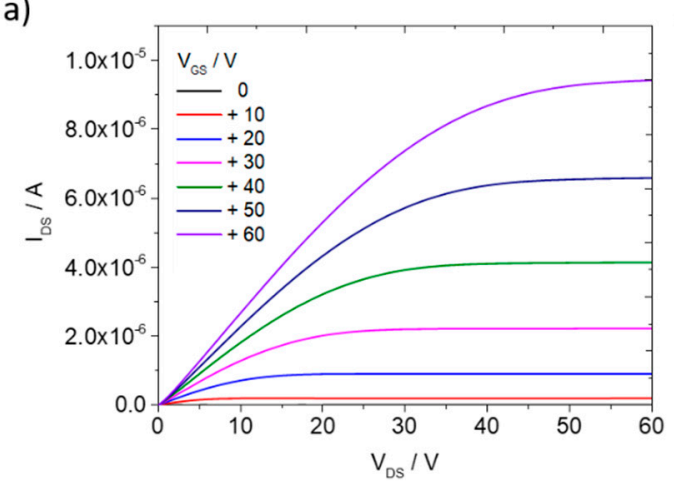

c)

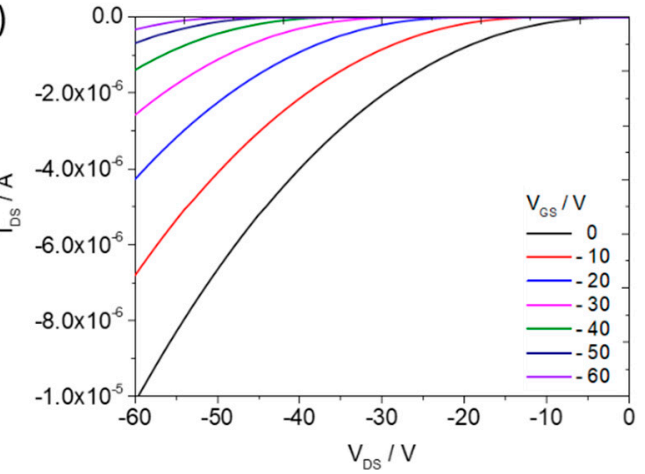

b)

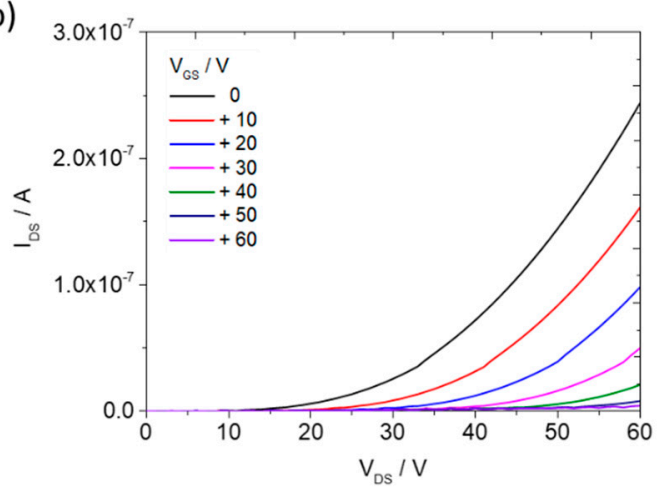

d)

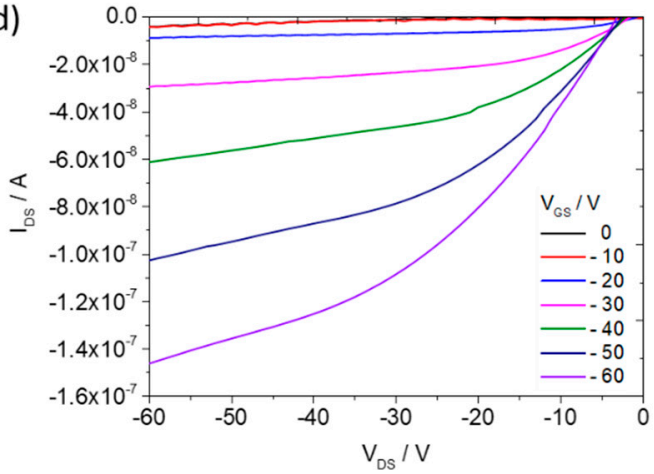

Figure 8. Output characteristics of OFETs based on PBTTT-C $\mathrm{C}_{14}$ :PDI8-CN $\mathrm{CN}_{2} \mathrm{BHJ}$ film fabricated at $4000 \mathrm{rpm}$ from $100{ }^{\circ} \mathrm{C}$ hot solution on OTS modified $\mathrm{Si}_{/} \mathrm{SiO}_{2}$ substrate for $(\mathbf{a}, \mathbf{b}) \mathrm{n}$ - and $(\mathbf{c}, \mathbf{d})$ p-type regimes; $(\mathbf{a}, \mathbf{c})$ before and $(\mathbf{b}, \mathbf{d})$ after annealing at $200^{\circ} \mathrm{C}$.

\section{Conclusions}

$\mathrm{BHJ}$ films were solution-processed using a blend of two semiconductors, p-type polymer PBTTT- $\mathrm{C}_{14}$ and n-type small molecule PDI8- $\mathrm{CN}_{2}$ applied as an active layer in OFETs. The thin film morphology depended on rotation speed, solution temperature and thermal annealing. In the as-cast $\mathrm{BHJ}$ films, the semiconductors phase separated into a disordered PBTTT- $\mathrm{C}_{14}$ phase and a PDI8- $\mathrm{CN}_{2}$ crystal network leading to a unipolar electron transport in OFETs. During annealing, less than $25 \mu \mathrm{m}$ long PDI8- $\mathrm{CN}_{2}$ crystals were grown on the top of the film surface. Since the length of the crystals was smaller than the channel length of the OFETs, the electron transport between source and drain electrodes was interrupted, while the hole conduction was established through the PBTTT- $\mathrm{C}_{14}$ polymer phase. By changing the processing parameters of the $\mathrm{BHJ}$ films, especially by the post-treatment, the transistor operation is switched from unipolar n-type to unipolar p-type. This concept can be further developed for a new generation of high performance and unipolar blend films for complementary circuits. Changing the unipolarity of OFETs after fabrication would simplify the fabrication of inverters on large-area substrates. Large-area substrates could be covered by the active $\mathrm{BHJ}$ film in one solution-processing step and then subsequently annealed leading to the array of p- and n-type devices.

Supplementary Materials: The following are available online at http://www.mdpi.com/2073-4360/12/11/2662/s1,

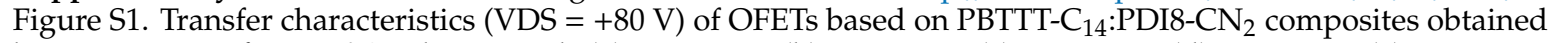
by spin-coating for $100^{\circ} \mathrm{C}$ solution and: (a) $1000 \mathrm{rpm}$, (b) $2000 \mathrm{rpm}$, (c) $3000 \mathrm{rpm}$, (d) $4000 \mathrm{rpm}$, (e) $5000 \mathrm{rpm}$, (f) $6000 \mathrm{rpm}$ rotation speeds. Table S1. Field-effect mobility values for PBTTT- $\mathrm{C}_{14}:$ PDI8-CN $\mathrm{CN}_{2}$ composites obtained by spin-coating for $100^{\circ} \mathrm{C}$ solution and different rotation speeds. Figure S2. Transfer characteristic $\left(V_{D S}=-80 \mathrm{~V}\right)$ of OFETs based on PBTTT-C 14 :PDI8-CN $\mathrm{CN}_{2}$ composites fabricated with rotation speed of $4000 \mathrm{rpm}$ and solutions at (a) $80{ }^{\circ} \mathrm{C}$, (b) $100{ }^{\circ} \mathrm{C}$, (c) $120{ }^{\circ} \mathrm{C}$, (d) $140{ }^{\circ} \mathrm{C}$. Table S2. Field-effect mobility values for PBTTT-C $14:$ PDI8-CN $_{2}$ composites fabricated with rotation speed of $4000 \mathrm{rpm}$ and different solution temperatures. Figure S3. AFM images of solution temperature dependence for PBTTT- $\mathrm{C}_{14}$ :PDI8- $\mathrm{CN}_{2}$ heterojunction composites additionally annealed at $200^{\circ} \mathrm{C}$. PBTTT-C $14:$ PDI8-CN ${ }_{2}$ films obtained at: (a) $80^{\circ} \mathrm{C}$, (b) $100^{\circ} \mathrm{C}$, (c) $120^{\circ} \mathrm{C}$, (d) $140{ }^{\circ} \mathrm{C}$, (e) $160^{\circ} \mathrm{C}$, (f) $180^{\circ} \mathrm{C}$. 
Figure S4. Transfer characteristic $\left(\mathrm{V}_{\mathrm{DS}}=-80 \mathrm{~V}\right)$ of OFETs based on PBTTT- $\mathrm{C}_{14}$ :PDI8-CN 2 composite with rotation speed of 3000 for various solution temperature after annealing at $140{ }^{\circ} \mathrm{C}$. Figure S5. Transfer characteristic of OFETs based on PBTTT-C 14 :PDI8-CN $\mathrm{CN}_{2}$ composite with rotation speed of $4000 \mathrm{rpm}(\mathrm{a})$ p-type $\left(\mathrm{V}_{\mathrm{DS}}=-80 \mathrm{~V}\right)$ and (b) n-type $\left(\mathrm{V}_{\mathrm{DS}}=+80 \mathrm{~V}\right)$ behavior. Figure S6. Transfer characteristic of OFETs based on PBTTT-C $14: \mathrm{PDI}-\mathrm{CN}_{2}$ composite fabricated with rotation speed of $4000 \mathrm{rpm}$ on substrate modified by OTS; (a) before annealing-n-type type $\left(\mathrm{V}_{\mathrm{DS}}=+60 \mathrm{~V}\right)(\mathrm{b})$ annealed at $200{ }^{\circ} \mathrm{C}-\mathrm{p}$-type $\left(\mathrm{V}_{\mathrm{DS}}=-60 \mathrm{~V}\right)$. Table S3. Field-effect mobility values for PBTTT-C 14 :PDI8-CN ${ }_{2}$ composites fabricated with rotation speed of $4000 \mathrm{rpm}$ on substrate modified by OTS. Figure S6. Vertical ( $\mathrm{q}_{\mathrm{z}} /$ vert.-upper plots) and horizontal ( $\mathrm{q}_{\mathrm{x}, \mathrm{y}}$, horiz-lower plots) integrations of GIWAXS patterns shown in Figure 6 in the main part of the paper. The integrations correspond to PBTTT-C14 (a), annealed PBTTT- ${ }_{\mathrm{C} 14}$ (b), PBTTT- ${ }_{\mathrm{C} 14}:$ PDI8- $\mathrm{CN}_{2}$ blend (c), and the annealed PBTTT-C $14: \mathrm{PDI}-\mathrm{CN}_{2}$ (d). In the horizontal integrations of PBTTT- $\mathrm{C}_{14}$ the deconvolution of patterns is included. Open points correspond to the experimental data, color lines show contributions of the $\pi-\pi$-stacking components and amorphous halos whereas black solid line correspond to the fitted data. If not specified otherwise Miller hkl indices correspond to crystal structure of PBTTT- $\mathrm{C}_{14}$. Table S4. PBTTT- $\mathrm{C}_{14}$ crystal structure parameters extracted from GIWAXS data shown in Figure S6. qmax, d, and t denote, respectively, peak position, interplanar spacing and crystal coherence length (Scherrer coherence) 100 and $\pi-\pi$ subscripts correspond to 100 interplanar distance and $\pi-\pi$ stacking distance. Since in PBTTT-C14 there are two distinct $\pi-\pi$ systems (see main text for details) there are $\pi-\pi_{1}$ and $\pi-\pi_{2}$ symbols.

Author Contributions: Data analysis, writing of original draft and editing, J.F.; sample fabrication, W.W.; manuscript review and editing, P.S., W.P., T.M.; GIWAXS analysis and manuscript preparation, A.K.; experiments and data analysis, T.M.; supervision, W.P., T.M.; funding acquisition, W.P., T.M. All authors have read and agreed to the published version of the manuscript.

Funding: This research was funded by the Foundation for Polish Science financed by the European Union under the European Regional Development Fund (POIR.04.04.00-00-3ED8/17-01), the National Science Centre, Poland, through the grant UMO-2015/18/E/ST3/00322 and National Science Centre, Poland through the grant UMO-2016/22/E/ST5/00472.

Acknowledgments: The authors acknowledge Ingo Lieberwirth and Gunnar Glaßer for SEM measurements. J. Fidyk, P. Sleczkowski and T. Marszalek acknowledge the Foundation for Polish Science financed by the European Union under the European Regional Development Fund (POIR.04.04.00-00-3ED8/17-01). W. Waliszewski and W. Pisula acknowledge the National Science Centre, Poland, through the grant UMO-2015/18/E/ST3/00322. A. Kiersnowski thanks National Science Centre, Poland for funding through the grant UMO-2016/22/E/ST5/00472. We gratefully acknowledge the DELTA electron storage ring in Dortmund (Germany) for a beamtime enabling GIWAXS measurements.

Conflicts of Interest: The authors declare no conflict of interest.

\section{References}

1. Yi, H.T.; Payne, M.M.; Anthony, J.E.; Podzorov, V. Ultra-flexible solution-processed organic field-effect transistors. Nat. Commun. 2012, 3, 1-7. [CrossRef]

2. Diao, Y.; Tee, B.C.K.; Giri, G.; Xu, J.; Kim, D.H.; Becerril, H.A.; Stoltenberg, R.M.; Lee, T.H.; Xue, G.; Mannsfeld, S.C.B.; et al. Solution coating of large-area organic semiconductor thin films with aligned single-crystalline domains. Nat. Mater. 2013, 12, 665-671. [CrossRef] [PubMed]

3. Tseng, H.Y.; Subramanian, V. All inkjet-printed, fully self-aligned transistors for low-cost circuit applications. Org. Electron. 2011, 12, 249-256. [CrossRef]

4. Zhou, K.; Dong, H.; Zhang, H.L.; Hu, W. High performance n-type and ambipolar small organic semiconductors for organic thin film transistors. Phys. Chem. Chem. Phys. 2014, 16, 22448-22457. [CrossRef] [PubMed]

5. Jiang, H.; Hu, W. The Emergence of Organic Single-Crystal Electronics. Angew. Chemie-Int. Ed. 2020, 59, 1408-1428. [CrossRef]

6. Liu, S.; Li, C.; Xu, X.; You, P.; Wang, N.; Wang, J.; Miao, Q.; Yan, F. Efficiency enhancement of organic photovoltaics by introducing high-mobility curved small-molecule semiconductors as additives. J. Mater. Chem. A 2019, 7, 12740-12750. [CrossRef]

7. Dai, F.; Liu, X.; Yang, T.; Qian, J.; Li, Y.; Gao, Y.; Xiong, P.; Ou, H.; Wu, J.; Kanehara, M.; et al. Fabrication of two-dimensional crystalline organic films by tilted spin coating for high-performance organic field-effect transistors. ACS Appl. Mater. Interfaces 2019, 11, 7226-7234. [CrossRef]

8. Trefz, D.; Gross, Y.M.; Dingler, C.; Tkachov, R.; Hamidi-Sakr, A.; Kiriy, A.; McNeill, C.R.; Brinkmann, M.; Ludwigs, S. Tuning Orientational Order of Highly Aggregating P(NDI2OD-T2) by Solvent Vapor Annealing and Blade Coating. Macromolecules 2019, 52, 43-54. [CrossRef]

9. Sun, Y.; Lu, J.; Ai, C.; Wen, D.; Bai, X. Enhancement of memory margins in the polymer composite of [6,6]-phenyl-C 61 -butyric acid methyl ester and polystyrene. Phys. Chem. Chem. Phys. 2016, 18, 30808-30814. [CrossRef] 
10. Ghittorelli, M.; Lenz, T.; Sharifi Dehsari, H.; Zhao, D.; Asadi, K.; Blom, P.W.M.; Kovács-Vajna, Z.M.; De Leeuw, D.M.; Torricelli, F. Quantum tunnelling and charge accumulation in organic ferroelectric memory diodes. Nat. Commun. 2017, 8, 2-9. [CrossRef]

11. Wu, K.; Zhang, S.; Xu, Z.; Chen, X.; Li, L. Solution-Processed Organic Complementary Inverters Based on TIPS-Pentacene and PDI8-CN2. IEEE Trans. Electron Devices 2015, 62, 4220-4224. [CrossRef]

12. Li, M.; Mangalore, D.K.; Zhao, J.; Carpenter, J.H.; Yan, H.; Ade, H.; Yan, H.; Müllen, K.; Blom, P.W.M.; Pisula, W.; et al. Integrated circuits based on conjugated polymer monolayer. Nat. Commun. 2018, 9. [CrossRef] [PubMed]

13. Khim, D.; Baeg, K.J.; Caironi, M.; Liu, C.; Xu, Y.; Kim, D.Y.; Noh, Y.Y. Control of ambipolar and unipolar transport in organic transistors by selective inkjet-printed chemical doping for high performance complementary circuits. Adv. Funct. Mater. 2014, 24, 6252-6261. [CrossRef]

14. Ren, Y.; Yang, X.; Zhou, L.; Mao, J.Y.; Han, S.T.; Zhou, Y. Recent Advances in Ambipolar Transistors for Functional Applications. Adv. Funct. Mater. 2019, 29, 1-65. [CrossRef]

15. Chen, Z.; Wei, X.; Huang, J.; Zhou, Y.; Zhang, W.; Pan, Y.; Yu, G. Multisubstituted Azaisoindigo-Based Polymers for High-Mobility Ambipolar Thin-Film Transistors and Inverters. ACS Appl. Mater. Interfaces 2019, 11, 34171-34177. [CrossRef] [PubMed]

16. Park, S.; Lee, B.; Bae, B.; Chai, J.; Lee, S.; Kim, C. Ambipolar thin-film transistors based on organic semiconductor blend. Synth. Met. 2019, 253, 40-47. [CrossRef]

17. Dong, H.; Fu, X.; Liu, J.; Wang, Z.; Hu, W. 25th Anniversary Article: Key Points for High-Mobility Organic Field-Effect Transistors. Adv. Mater. 2013, 25, 6158-6183. [CrossRef]

18. Liu, C.; Xu, Y.; Noh, Y.Y. Contact engineering in organic field-effect transistors. Mater. Today 2015, 18, 79-96. [CrossRef]

19. Kotadiya, N.B.; Lu, H.; Mondal, A.; Ie, Y.; Andrienko, D.; Blom, P.W.M.; Wetzelaer, G.J.A.H. Universal strategy for Ohmic hole injection into organic semiconductors with high ionization energies. Nat. Mater. 2018, 17, 329-334. [CrossRef]

20. Zhang, K.; Kotadiya, N.B.; Wang, X.; Wetzelaer, G.J.A.H.; Marszalek, T.; Pisula, W.; Blom, P.W.M. Hole injection layers for improving charge carrier injection in organic field effect transistors. Adv. Electron. Mater. 2020, 6, 1901352. [CrossRef]

21. Salzillo, T.; Campos, A.; Mas-Torrent, M. Solution-processed thin films of a charge transfer complex for ambipolar field-effect transistors. J. Mater. Chem. C 2019, 7, 10257-10263. [CrossRef]

22. Wang, H.; Yan, D. Organic heterostructures in organic field-effect transistors. NPG Asia Mater. 2010, 2, 69-78. [CrossRef]

23. Wang, S.; Zhang, H.; Zhang, B.; Xie, Z.; Wong, W.Y. Towards high-power-efficiency solution-processed OLEDs: Material and device perspectives. Mater. Sci. Eng. R Rep. 2020, 140, 100547. [CrossRef]

24. Scharber, M.C.; Sariciftci, N.S. Efficiency of bulk-heterojunction organic solar cells. Prog. Polym. Sci. 2013, 38, 1929-1940. [CrossRef]

25. Lüssem, B.; Keum, C.M.; Kasemann, D.; Naab, B.; Bao, Z.; Leo, K. Doped Organic Transistors. Chem. Rev. 2016, 116, 13714-13751. [CrossRef]

26. Chiba, T.; Kumagai, D.; Udagawa, K.; Watanabe, Y.; Kido, J. Dual mode OPV-OLED device with photovoltaic and light-emitting functionalities. Sci. Rep. 2018, 8, 1-7. [CrossRef]

27. Nam, M.; Cha, M.; Lee, H.H.; Hur, K.; Lee, K.T.; Yoo, J.; Han, I.K.; Kwon, S.J.; Ko, D.H. Long-term efficient organic photovoltaics based on quaternary bulk heterojunctions. Nat. Commun. 2017, 8, 1-10. [CrossRef]

28. Puniredd, S.R.; Kiersnowski, A.; Battagliarin, G.; Zajaczkowski, W.; Wong, W.W.H.; Kirby, N.; Mullen, K.; Pisula, W. Polythiophene-perylene diimide heterojunction field-effect transistors. J. Mater. Chem. C 2013, 1, 2433-2440. [CrossRef]

29. Hunter, S.; Chen, J.; Anthopoulos, T.D. Microstructural Control of Charge Transport in Organic Blend Thin-Film Transistors. Adv. Funct. Mater. 2014, 24, 5969-5976. [CrossRef]

30. He, Z.; Zhang, Z.; Bi, S.; Chen, J.; Li, D. Conjugated Polymer Controlled Morphology and Charge Transport of Small-Molecule Organic Semiconductors. Sci. Rep. 2020, 10, 1-10. [CrossRef]

31. Chou, L.H.; Na, Y.; Park, C.H.; Park, M.S.; Osaka, I.; Kim, F.S.; Liu, C.L. Semiconducting small molecule/polymer blends for organic transistors. Polymer 2020, 191, 122208. [CrossRef]

32. Tsao, H.N.; Pisula, W.; Liu, Z.; Osikowicz, W.; Salaneck, W.R.; Müllen, K. From ambi- To unipolar behavior in discotic dye field-effect transistors. Adv. Mater. 2008, 20, 2715-2719. [CrossRef] [PubMed] 
33. Hunter, S.; Anthopoulos, T.D. Observation of unusual, highly conductive grain boundaries in high-mobility phase separated organic semiconducting blend films probed by lateral-transport conductive-AFM. Adv. Mater. 2013, 25, 4320-4326. [CrossRef] [PubMed]

34. Reichenberger, M.; Kroh, D.; Matrone, G.M.M.; Schötz, K.; Pröller, S.; Filonik, O.; Thordardottir, M.E.; Herzig, E.M.; Bässler, H.; Stingelin, N.; et al. Controlling aggregate formation in conjugated polymers by spin-coating below the critical temperature of the disorder-order transition. J. Polym. Sci. Part B Polym. Phys. 2018, 56, 532-542. [CrossRef]

35. McCulloch, I.; Heeney, M.; Bailey, C.; Genevicius, K.; MacDonald, I.; Shkunov, M.; Sparrowe, D.; Tierney, S.; Wagner, R.; Zhang, W.; et al. Liquid-crystalline semiconducting polymers with high charge-carrier mobility. Nat. Mater. 2006, 5, 328-333. [CrossRef]

36. Snyder, C.R.; Kline, R.J.; Delongchamp, D.M.; Nieuwendaal, R.C.; Richter, L.J.; Heeney, M.; McCulloch, I. Classification of semiconducting polymeric mesophases to optimize device postprocessing. J. Polym. Sci. Part B Polym. Phys. 2015, 53, 1641-1653. [CrossRef]

37. Delongchamp, D.M.; Kline, R.J.; Jung, Y.; Lin, E.K.; Fischer, D.A.; Gundlach, D.J.; Cotts, S.K.; Moad, A.J.; Richter, L.J.; Toney, M.F.; et al. Molecular basis of mesophase ordering in a thiophene-based copolymer. Macromolecules 2008, 41, 5709-5715. [CrossRef]

38. Rivnay, J.; Jimison, L.H.; Northrup, J.E.; Toney, M.F.; Noriega, R.; Lu, S.; Marks, T.J.; Facchetti, A.; Salleo, A. Large modulation of carrier transport by grain-boundary molecular packing and microstructure in organic thin films. Nat. Mater. 2009, 8, 952-958. [CrossRef]

39. Cochran, J.E.; Junk, M.J.N.; Glaudell, A.M.; Miller, P.L.; Cowart, J.S.; Toney, M.F.; Hawker, C.J.; Chmelka, B.F.; Chabinyc, M.L. Molecular interactions and ordering in electrically doped polymers: Blends of PBTTT and F4TCNQ. Macromolecules 2014, 47, 6836-6846. [CrossRef]

40. Jones, B.A.; Facchetti, A.; Wasielewski, M.R.; Marks, T.J. Tuning orbital energetics in arylene diimide semiconductors. Materials design for ambient stability of n-type charge transport. J. Am. Chem. Soc. 2007, 129, 15259-15278. [CrossRef]

41. Kotadiya, N.B.; Mondal, A.; Blom, P.W.M.; Andrienko, D.; Wetzelaer, G.J.A.H. A window to trap-free charge transport in organic semiconducting thin films. Nat. Mater. 2019, 18, 1182-1186. [CrossRef] [PubMed]

42. Yim, K.-H.; Whiting, G.L.; Murphy, C.E.; Halls, J.J.M.; Burroughes, J.H.; Friend, R.H.; Kim-Seon, J. Controlling Electrical Properties of Conjugated Polymersvia a Solution-Based p-Type Doping. Adv. Mater. 2008, 20, 3319-3324. [CrossRef]

43. Bardagot, O.; Kubik, P.; Marszalek, T.; Veyre, P.; Medjahed, A.A.; Sandroni, M.; Grévin, B.; Pouget, S.; Domschke, T.N.; Carella, A.; et al. Impact of Morphology on Charge Carrier Transport and Thermoelectric Properties of N-Type FBDOPV-Based Polymers. Adv. Funct. Mater. 2020, 30, 2000449. [CrossRef]

44. Braga, D.; Horowitz, G. High-Performance organic field-effect transistors. Adv. Mater. 2009, 21, $1473-1486$. [CrossRef]

45. Horowitz, G. Organic thin film transistors: From theory to real devices. J. Mater. Res. 2004, 19, $1946-1962$. [CrossRef]

46. Yang, Y.; Liu, J.; Guo, T.-F.; Shi, Y. The Control of Morphology and the Morphological Dependence of Device Electrical and Optical Properties in Polymer Electronics; Hotta, S., Ed.; Research Signpost: Kerala, India, 2003; Volume 661, ISBN 81-7736-083-3.

47. Chlebosz, D.; Janasz, Ł.; Janus, K.; Gazińska, M.; Goldeman, W.; Ulanski, J.; Pisula, W.; Kiersnowski, A. Formation, growth and transformations of crystalline phases in solution-cast blends of poly(3-hexylthiopehene) and perylene dicarboximides. Dye. Pigment. 2017, 140, 491-499. [CrossRef]

48. Li, L.H.; Kontsevoi, O.Y.; Rhim, S.H.; Freeman, A.J. Structural, electronic, and linear optical properties of organic photovoltaic PBTTT-C14 crystal. J. Chem. Phys. 2013, 138. [CrossRef]

Publisher's Note: MDPI stays neutral with regard to jurisdictional claims in published maps and institutional affiliations. 